and demonstrated the importance of milk as a source of iodine in the diet.

We are grateful to Dr. J. S. Milne for arranging for the delivery of milk from Edinburgh and to Mrs. D. Bingham for supply of milk and for assistance in keeping records of the feeding of cows. Miss G. Gillott gave valuable technical help. The work was supported by grants from the Endowment Fund of the United Sheffield Hospitals, the Wellcome Trust, and the Medical Research Council.

\section{REFERENCES}

Acland, J. D. (1957). Biochem. f., 66, 177.

Annual Report of National Food Survey Committee (1963). Domestic Food Consumption and Expenditure, 1961. H.M.S.O., London.

Boulangé, M. (1959). C.R. Soc. Biol. (Paris), 153, 2019.

Bowler, R. G. (1944). Biochem. F., 38, 385.
Chilean Iodine Educational Bureau (1952). Iodine Content of Foods. London.

Hughes, D. E., Rodgers, K., and Wilson, D. C. (1959). Brit. med. F., 1 , 280.

Inglis, J. (1838). Treatise on English Bronchocele, With a Few Remarks on the Use of Iodine and Its Compounds. Longmans, London.

Kilpatrick, R., Milne, J. S., Rushbrooke, M., Wilson, E. S. B., and Wilson, G. M. (1963). Brit. med. F., 1, 29.

Medical Research Council (1936). Spec. Rep. Ser. med. Res. Coun. (Lond.), No. 217.

Murray, M. M., Ryle, J. A., Simpson, B. W., and Wilson, D. C. (1948). Memor. Med. Res. Coun. (Lond.), No. 18.

Powell, F. J. N. (1953). 7. clin. Path., 6, 286.

Riggs, D. S. (1952). Pharmacol. Rev., 4, 284.

Stanbury, J. B. (1960). Wld Hith Org. Monogr. Ser., No. 44, p. 261 . Brownell, G. L., Riggs, D. S., Perinetti, H., Itoiz, J., and Del
Castillo, E. B. (1954). Endemic Goitre. Harvard University Press, Cambridge, Mass.

Vilkki, P. (1956). Ann. Acad. Sci. fenn. A 11, 71, 7.

Vought, R. L., and London, W. T. (1964). Amer. f. clin. Nutr., 14, 186. 1218 .

Wayne, E. J., Koutras, D. A., and Alexander, W. D. (1964). Clinical Aspects of Iodine Metabolism. Blackwell, Oxford.

\title{
Total Correction of Tetralogy of Fallot in Young Children
}

\author{
I. K. R. MCMILLAN,* M.B., B.CHIR., F.R.C.S. ; A. M. JOHNSON,† M.D., M.R.C.P.; E. S. MACHELL, F F.F.A. R.C.S.
}

Brit. med. F., 1965, 1, 348-350

The introduction of a technique for performing total correction of the tetralogy of Fallot under cardiopulmonary by-pass was reported by Lillehei et al. (1955).

In spite of successes in children under 5 years reported by Lillehei et al., most centres have avoided performing total correction in the group under 5 owing to the high operative mortality.

In our initial experience in this unit we did not attempt total correction in children weighing less than $15 \mathrm{~kg}$., but with improved and modified techniques using deep hypothermia we have been able to reduce the lower weight limit. In this paper we report the results in 14 small children weighing between 7 and $17 \mathrm{~kg}$. and aged 10 months to 4 years 7 months (Table I). During the same period of time 34 children aged up to 5 years were seen with the tetralogy of Fallot. In two infants a Blalock operation was performed and the other 18 children remain under observation. It must be emphasized that in all of the 14 cases totally corrected the symptoms were severe (Table II) and it was thought that the child would not survive without surgical relief of one or other type.

\section{Method}

With the small hearts of these patients the driest possible operative field was required, and accordingly the principle of circulatory arrest with deep hypothermia was employed in most cases. The principle is the same as that described by Drew et al. (1959), but an oxygenator was used with the standard heart-lung circuit and not the lungs as in his method.

The patients were anaesthetized with nitrous oxide and curare after induction with cyclopropane and oxygen. The chest was opened by median sternotomy and at the same time the left femoral artery and left saphenous vein were prepared.

Arterial pressure was monitored through a catheter in a radial artery or by a side arm from the femoral arterial cannula

\footnotetext{
* Consultant Thoracic Surgeon, Wessex Cardiac and Thoracic Centre, Southampton Chest Hospital

t Consultant Cardiologist, Wessex Cardiac and Thoracic Centre, Southampton Chest Hospital

$\ddagger$ Consultant Anaesthetist, Southampton Chest Hospital.
}

if a sphygmomanometric reading was not easily obtainable. Superior and inferior vena caval pressures were also monitored, together with the electrocardiogram and the electroencephalogram.

The pericardium was opened longitudinally and tapes were passed round the superior and inferior venae cavae and ascending aorta. At this stage the right atrium was explored and the presence of a patent foramen ovale was confirmed or excluded. The patient was then heparinized and the venous cannulae were inserted into the venae cavae. These cannulae were joined by a Y-tube to a venous line, draining by gravity into the pump-oxygenator. In some cases a single metal Drew cannula was inserted into the right atrium. The oxygenator used was the Raison (1963) infant modification of the standard Melrose (1959) N.E.P. machine. The arterial side was connected through a filter and heat exchanger to the left femoral artery cannula in the usual way. Partial perfusion was then instituted and the temperature slowly but steadily reduced, taking from 30 to 60 minutes according to the size of the patient. By monitoring muscle, rectal, nasopharyngeal, and oesophageal temperatures any excessive blood-tissue temperature gradients were avoided.

\begin{tabular}{|c|c|c|c|c|c|}
\hline \multirow{2}{*}{$\begin{array}{l}\text { Case } \\
\text { No. }\end{array}$} & \multicolumn{2}{|c|}{ Age } & \multirow{2}{*}{ Operation Date } & \multirow{2}{*}{ Result } & \multirow{2}{*}{$\begin{array}{l}\text { Follow-up } \\
\text { (Months) }\end{array}$} \\
\hline & Years & Months & & & \\
\hline $\begin{array}{r}1 \\
2 \\
3 \\
4 \\
5 \\
6 \\
7 \\
8 \\
9 \\
10 \\
11 \\
12 \\
13 \\
14\end{array}$ & $\begin{array}{l}\overline{4} \\
2 \\
2 \\
2 \\
1 \\
2 \\
4 \\
3 \\
3 \\
3 \\
1 \\
4 \\
4\end{array}$ & $\begin{array}{r}10 \\
0 \\
3 \\
3 \\
0 \\
4 \\
11 \\
0 \\
6 \\
2 \\
3 \\
6 \\
7 \\
6\end{array}$ & $\begin{array}{l}\text { March } 1962 \\
\text { July } 1962 \\
\text { Sept. } 1962 \\
\text { Oct. } 1962 \\
\text { Nov. } 1962 \\
\text { Jan. } 1963 \\
\text { March } 1963 \\
\text { July } 1963 \\
\text { Dec. } 1963 \\
\text { Jan. } 1964 \\
\text { Feb. } 1964 \\
\text { March } 1964 \\
\text { May } 1964 \\
\text { June } 1964\end{array}$ & $\begin{array}{l}\text { Good } \\
\text { ", } \\
\text { ", } \\
\text { Improved } \\
\text { Good } \\
\text { Fä; } \\
\text { Dead } \\
\text { Good } \\
\text { Dead } \\
\text { Good } \\
\text { ", }\end{array}$ & $\begin{array}{l}27 \\
24 \\
21 \\
20 \\
19 \\
17 \\
15 \\
11 \\
= \\
\frac{5}{2} \\
11\end{array}$ \\
\hline
\end{tabular}

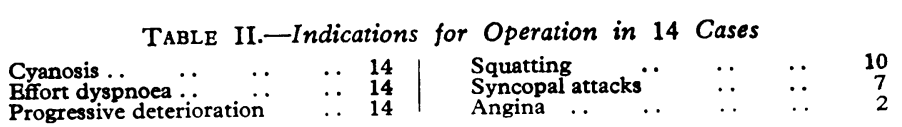


A vent was inserted into the apex of the left ventricle in all cases and drained to the oxygenator, to prevent distension of the left heart. At no stage was the perfusion converted to total by occluding the venae cavae alone, as it was important to avoid distension of the right heart from coronary sinus return. The perfusion rate was initially 2.4 litres per minute per square metre of body surface area ; and when the temperature reached the low twenties it was reduced to a rate adequate to maintain perfusion pressure and oxygenation. When the temperature had reached about $18^{\circ}$ C. a transverse incision was made in the right ventricle just below the infundibulum and resection of infundibular stenosis or hypertrophy, if present, was carried out. Between 12 and $14^{\circ} \mathrm{C}$. perfusion was halted and the right heart drained of blood while ascending aorta and venae cavae were occluded. Intracardiac blood was sucked out to give a dry field, and the defects were inspected to confirm the diagnosis and to assess anatomical details. Closure of the ventricular septal defect (V.S.D.) was then carried out either by direct suture or by means of a Teflon patch (Table III). With direct suture the stitches were placed as described by Sayed et al. (1962) and tied over Teflon felt. In the very small heart three or four stitches were usually sufficient. Next the pulmonary valve was inspected and, if stenosed, was divided from below. The pulmonary artery was usually too small to allow a supravalvar approach. As soon as the defect was closed, with correction of the override, and when the outflow tract and pulmonary valve were satisfactory (Table III), perfusion was restarted after releasing the clamps.

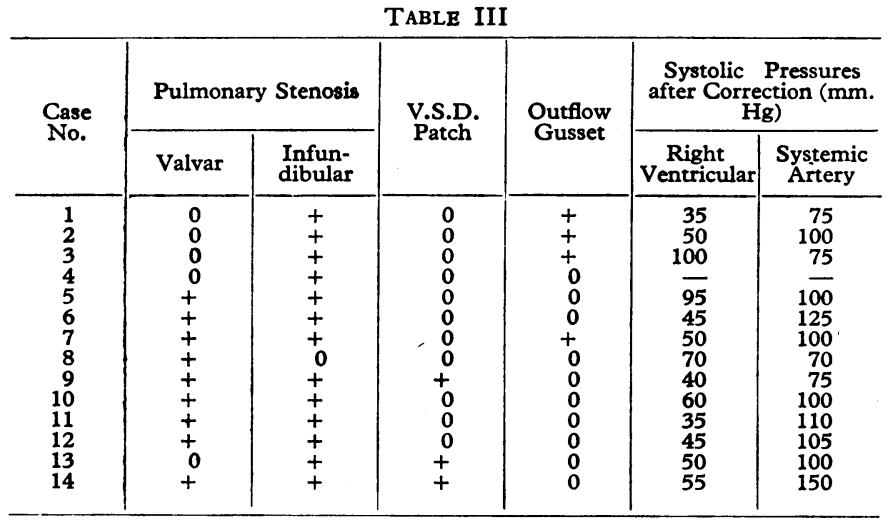

When perfusion was recommenced the temperature was not raised for some minutes in order to eliminate oxygen debt before active rewarming started. During this time a gusset of Teflon felt lined with pericardium was inserted into the outflow tract if necessary (Table III) and sewn into position while rewarming continued. No patch was placed across the pulmonary valve ring in any case. In most cases the heart, which was stopped, restarted spontaneously. If it did not do so, ventricular defibrillation was carried out at about $25^{\circ} \mathrm{C}$. When the temperature reached $34^{\circ} \mathrm{C}$. the left ventricular vent was clamped; the clamp was removed if the heart was beating steadily. At the same time right-ventricular closure was completed. The foramen ovale, when present, was then closed through a separate right atrial incision. At 35 to $36^{\circ} \mathrm{C}$. the perfusion was slowly terminated and the circulation restored to normal. The period of circulatory arrest lasted between 20 and 50 minutes. If the heart-beat was satisfactory the venous cannulae were removed and protamine was given. When blood-clotting was normal the chest was closed with pericardial, mediastinal, and pleural drainage.

Serial blood samples were taken before, during, and after perfusion for measurement of blood electrolytes, $\mathrm{pH}, \mathrm{PCO}_{2}$, plasma haemoglobin, haemoghobin, and packed cell volume.

There were no renal complications, but all cases had lowmolecular-weight dextran (Rheomacrodex) added to the pump blood ( $20 \mathrm{ml} . / \mathrm{kg}$. body weight) and $40 \mathrm{ml}$. was added to each
$500 \mathrm{ml}$. of dextrose saline used in the post-operative period, in order to keep the haematocrit reading within normal limits.

Post-operatively, the I.V.C. catheter was left in place for four to five days to facilitate blood and fluid administration and the withdrawal of blood samples without disturbance to the child. The venous pressure was measured by the same route in most cases for the first few days and arterial samples were taken as necessary.

In only one of the first 12 cases was a patch used to close the V.S.D. After considering the three deaths from heartblock, however, in two of which block appeared for the first time some hours after operation, it was suspected that tension on the suture line following direct suture might have been responsible. For this reason it was decided to use patches more often, and this was carried out in the last two cases. They showed no heart-block at any stage.

\section{Results}

Fourteen cases were operated upon; 11 survived, with follow-up of $1 \frac{1}{2}$ to 27 months, and all were alive and well at the time of writing. Ten cases showed no cyanosis and the V.S.D. appeared to be closed on clinical, phonocardiographic, and radiological evidence. One case was greatly improved but remained cyanosed, and the V.S.D. was evidently open.

Three patients died within 6 to 48 hours after operation, all with heart-block.

Complications.-In Case 5 the patient was still cyanosed, although her exercise tolerance was greatly improved and she had had no more cyanotic attacks. The reopening of her V.S.D. may well have been due to the failure to reduce right ventricular pressure sufficiently at operation. Case 8 had complete heart-block treated by artificial pacemaker. Sinus rhythm returned in three weeks, but A.V. block had been present intermittently ever since. Fortunately he had no symptoms associated with this. Three patients died of complete heartblock. One of these developed block during the operation, while the other two acquired it some hours after operation. There were no cases of post-operative renal failure. No case had any severe post-operative respiratory failure or needed tracheostomy. There were no problems with post-operative bleeding.

\section{Discussion}

Considerable argument against total correction of Fallot's tetralogy, as opposed to palliative operation, is still raised. This series of cases, while admittedly small, nevertheless shows that total correction is possible with acceptable risk in these cases.

At present $7 \mathrm{~kg}$. is our lower weight limit, and with improvements in perfusion apparatus it may well be possible to lower the limit further. The main problems are now cannulation in the infant and surgical procedures inside the very small heart.

For infants under this weight we continue to do either a shunt operation or a transventricular pulmonary valvotomy. It should be emphasized again that we do not recommend total correction as a routine in all cases of Fallot's tetralogy, but only in those in whom an operation at this time is necessary to maintain life. It is agreed that in many cases surgery can be postponed until the child is older.

It has not always proved possible to reduce the right ventricular pressure greatly at operation (Table III). In Cases 3 and 5 severe right ventricular hypertension remained. In Case 3 it was well tolerated, but in Case 5 it probably caused the reopening of the V.S.D.

It is felt that the size of the V.S.D. and its suitability for closure by direct suture cannot be properly judged in the arrested hypothermic heart and that this assessment must be made with the heart open but still beating. If it is then evident 
that closure of the defect will be difficult without the use of cardiac arrest, the temperature can be lowered to the correct level and closure be performed under optimal conditions.

In one case where the defect was closed by direct suture, one suture tore out and so damaged the septum that a patch had to be overlaid to cover the tear. Unfortunately, in suturing this patch into position tricuspid incompetence was produced. The development of heart-block some 18 hours later was attributed to gross right ventricular dilatation causing tension on the sutures.

Three of the four patients who developed heart-block had unusual anatomical features in relation to the V.S.D. Sayed et al. (1961) showed the usual anatomy of the V.S.D. in the tetralogy of Fallot. In our experience, any departure from this pattern greatly increases the risk of heart-block occurring during closure or if distension of either ventricle produces tension in the V.S.D. sutures post-operatively.

The prophylactic insertion of a cardiac pacemaker electrode is now carried out to facilitate the immediate treatment of heartblock of late onset.

Of the four cases with heart-block, the survivor responded normally to artificial pacemaking, while the other three, although they responded normally at first, rapidly developed an increasing resistance requiring voltage increase from 1.5 to 12 volts over 12 to 24 hours. They then became completely resistant to any stimulation, and death followed. No satisfactory explanation for this phenomenon can be offered.

In all three patients dying of heart-block, cerebral disturbance became manifest soon after the onset of the block and severe cerebral damage was found at necropsy.
It is encouraging that, contrary to expectation, no trouble was experienced with respiration in the post-operative phase and tracheostomy was not required. The children were nursed flat in an oxygen tent for 48 hours and were then gradually weaned from it.

In two cases the children were bottle-fed without difficulty, but in all cases great care is needed to preserve post-operative biochemical equilibrium.

\section{Summary}

Fourteen children under the age of 5 years were operated upon for total correction of the tetralogy of Fallot, using cardiopulmonary by-pass and deep hypothermia. There were three fatalities. Ten were acyanotic and well, while one was still cyanosed owing to reopening of the ventricular septal defect but was greatly improved. There were no respiratory or haemorrhagic complications.

We should like to thank Mr. H. M. Bradmore for his assistance at all these operations; Dr. M. Yorston, who provided anaesthesia ; the paediatricians of the Wessex Region who referred the patients; and the medical and nursing staff of the Cardiac and Thoracic Unit for their unstinted help, without which this work would not have been possible.

\section{REFERENCES}

Drew, C. E., Keen, G., and Benazon, D. B. (1959). Lancet, 1, 745. Lillehei, C. W., Cohen, M., Warden, H. E., Read, R. C., Aust, J. B., De Wall, R. A., and Varco, R. L. (1955). Ann. Surg., 142, 418. Melrose, D. G. (1959). Brit. F. Anaesth., 31, 393.

Raison, J. C. A. (1963). Thorax, 18, 98.

Sayed, H., Bentall, H., and Melrose, D. (1962). Lancet, 1, 549.

\title{
Diffuse Mesothelioma of the Pleura and Asbestos
}

\author{
P. C. ELMES,* M.D., M.R.C.P. ; W. T. E. MCCAUGHEY,† M.D. ; O. L. WADE,* M.D., F.R.C.P.
}

Brit. med. F., 1965, 1, 350-353

Diffuse mesothelioma of the pleura is an uncommon tumour which, after prolonged controversy, has now become generally accepted as an entity (Campbell, 1950; Godwin 1957; McCaughey, 1958 ; Wagner, Munday, and Harington, 1962). Evidence has recently been accumulating that inhalation of asbestos may be an important factor in the aetiology of this tumour, and groups of cases associated with exposure to asbestos have been reported from South Africa (Wagner, Sleggs, and Marchand, 1960), Germany (König, 1960), the United Kingdom (McCaughey, Wade, and Elmes, 1962 ; Hourihane, 1964 ; Owen, 1964), and the United States (Selikoff, Churg, and Hammond, 1964). Crocidolite, the blue asbestos mined in South Africa, appears to be particularly carcinogenic in this respect (Wagner et al., 1960). There is also evidence that similar tumours arising in the peritoneum are also related to asbestos exposure (Keal, 1960 ; Enticknap and Smither, 1964 ; Hourihane, 1964).

In a previous report (McCaughey et al., 1962) we described the finding of asbestos bodies in the lungs of 12 out of 15 patients who had died of diffuse pleural mesothelioma in Belfast. Details of the working life were available for only nine of these patients, but in four of them there was a clear history of exposure to asbestos. This paper describes three further

\footnotetext{
* Department of Therapeutics and Pharmacology, the Queen's University

t Department of Pathology, the Queen's University of Belfast.
}

investigations carried out in Belfast: (1) a study of the industrial occupation of 42 patients with mesothelioma of the pleura and of 42 control patients without mesothelioma; (2) an investigation of the prevalence of asbestos bodies in the lungs of patients with and without mesothelioma of the pleura or carcinoma of the lung; and (3) an investigation of the relation between the presence of asbestos bodies in the lungs at death and a history of exposure to asbestos.

\section{Industrial Occupation}

Patients with Mesothelioma of the Pleura.-Occupational histories were obtained from the patients themselves or, if the patients had died, from friends and neighbours. Including those previously reported, 45 cases of mesothelioma of the pleura had been diagnosed in Belfast by the time this study was completed. Only 42 were included in the analysis because three of the early patients had died more than 15 years previously and no details were available.

Control Patients.-Occupational histories were obtained from matched controls selected from the records of the department of pathology. If diagnosis of mesothelioma of the pleura in the propositus had been made by biopsy the paired control was selected as that patient of the same sex and within 1 year of age whose name appeared closest to the name of the 